Pacific Journal of Mathematics

CMMON FXED PONTT OF TWO MAPPND 


\section{COMMON FIXED POINTS OF TWO MAPPINGS}

\section{CHI SoNg WoNg}

Let $S, T$ be functions on a nonempty complete metric space $(X, d)$. The main result of this paper is the following. $S$ or $T$ has a fixed point if there exist decreasing functions $\alpha_{1}, \alpha_{2}, \alpha_{3}, \alpha_{4}, \alpha_{5}$ of $(0, \infty)$ into $[0,1)$ such that (a) $\sum_{i=1}^{5} \alpha_{i}<1$; (b) $\alpha_{1}=\alpha_{2}$ or $\alpha_{3}=\alpha_{4}$, (c) $\lim _{t \downarrow 0}\left(\alpha_{1}+\alpha_{2}\right)<1$ and $\lim _{t \downarrow 0}\left(\alpha_{3}+\alpha_{4}\right)<1$ and (d) for any distinct $x, y$ in $X$,

$$
\begin{aligned}
d(S(x), T(y)) \leqq & a_{1} d(x, S(x))+a_{2} d(y, T(y))+a_{3} d(x, T(y)) \\
& +a_{4} d(y, S(x))+a_{5} d(x, y),
\end{aligned}
$$

where $a_{i}=\alpha_{i}(d(x, y))$. A number of related results are obtained.

1. Introduction. Let $(X, d)$ be a nonempty complete metric space and let $S, T$ be mappings of $X$ into itself which are not necessarily continuous nor commuting. Suppose that there are nonnegative real numbers $a_{1}, a_{2}, a_{3}, a_{4}, a_{5}$ such that

$$
\begin{gathered}
a_{1}+a_{2}+a_{3}+a_{4}+a_{5}<1, \\
a_{1}=a_{2} \quad \text { or } \quad a_{3}=a_{4},
\end{gathered}
$$

and for any $x, y$ in $X$,

$$
\begin{aligned}
d(S(x), T(y)) \leqq & a_{1} d(x, S(x))+a_{2} d(y, T(y))+a_{3} d(x, T(y)) \\
& +a_{4} d(y, S(x))+a_{5} d(x, y) .
\end{aligned}
$$

It is proved in this paper that each of $S, T$ has a unique fixed point and these two fixed points coincide. Among others, a generalization is obtained by replacing $a_{1}, a_{2}, a_{3}, a_{4}, a_{5}$ with nonnegative real-valued functions on $(0, \infty)$. This result generalizes the Banach contraction mapping theorem and some results of G. Hardy and T. Rogers [5], R. Kannan [7], E. Rakotch [8], S. Reich [9], P. Srivastava, and V. K. Gupta [10]. It also gives a different proof for these special cases. Note that even if $X=[0,1]$ and if $T_{1}, T_{2}$ are commuting continuous functions of $X$ into itself, $T_{1}, T_{2}$ need not have a common fixed point [1], [2], and [6].

\section{Basic results.}

THEOREM 1. Let $S, T$ be mappings of a complete metric space $(X, d)$ into itself. Suppose that there exist nonnegative real numbers $a_{1}, a_{2}, a_{3}, a_{4}, a_{5}$ which satisfy (a), (b), and (c). Then each of $S, T$ 
has a unique fixed point and these two fixed points coincide.

Proof. Let $x_{0} \in X$. Define

$$
x_{2 n+1}=S\left(x_{2 n}\right), x_{2 n+2}=T\left(x_{2 n+1}\right), \quad n=0,1,2, \cdots .
$$

From (c),

$$
\begin{aligned}
d\left(x_{1}, x_{2}\right) & =d\left(S\left(x_{0}\right), T\left(x_{1}\right)\right) \\
& \leqq\left(a_{1}+a_{5}\right) d\left(x_{0}, x_{1}\right)+a_{2} d\left(x_{1}, x_{2}\right)+a_{3} d\left(x_{0}, x_{2}\right) \\
& \leqq\left(a_{1}+a_{5}\right) d\left(x_{0}, x_{1}\right)+a_{2} d\left(x_{1}, x_{2}\right)+a_{3}\left(d\left(x_{0}, x_{1}\right)+d\left(x_{1}, x_{2}\right)\right) .
\end{aligned}
$$

So

$$
d\left(x_{1}, x_{2}\right) \leqq \frac{a_{1}+a_{3}+a_{5}}{1-a_{2}-a_{3}} d\left(x_{0}, x_{1}\right)
$$

Similarly,

$$
d\left(x_{2}, x_{3}\right) \leqq \frac{a_{2}+a_{4}+a_{5}}{1-a_{1}-a_{4}} d\left(x_{1}, x_{2}\right)
$$

Let

$$
r=\frac{a_{1}+a_{3}+a_{5}}{1-a_{2}-a_{3}}, \quad s=\frac{a_{2}+a_{4}+a_{5}}{1-a_{1}-a_{4}} .
$$

Repeating the above argument, we obtain, for each $n=0,1,2, \cdots$,

$$
\begin{aligned}
& d\left(x_{2 n+1}, x_{2 n+2}\right) \leqq r d\left(x_{2 n+1}, x_{2 n}\right), \\
& d\left(x_{2 n+3}, x_{2 n+2}\right) \leqq \\
& s d\left(x_{2 n+2}, x_{2 n+1}\right) .
\end{aligned}
$$

By (3), (4), and induction, we have, for each $n=0,1,2, \cdots$,

$$
\begin{aligned}
& d\left(x_{2 n+1}, x_{2 n+2}\right) \leqq r(r s)^{n} d\left(x_{0}, x_{1}\right), \\
& d\left(x_{2 n+2}, x_{2 n+3}\right) \leqq(r s)^{n+1} d\left(x_{0}, x_{1}\right) .
\end{aligned}
$$

Since $r s<1$ and

$$
\sum_{n=0}^{\infty} d\left(x_{n}, x_{n+1}\right) \leqq(1+r) \sum_{n=0}^{\infty}(r s)^{n} d\left(x_{0}, x_{1}\right),
$$

$\left\{x_{n}\right\}$ is Cauchy. By completeness of $(X, d),\left\{x_{n}\right\}$ converges to some point $x$ in $X$. We shall now prove that $x$ is a fixed point of $S$ and $T$. Let $n$ be given. Then

$$
\begin{aligned}
d(x, S(x)) & \leqq d\left(x, x_{2 n+2}\right)+d\left(S(x), x_{2 n+2}\right) \\
& =d\left(x, x_{2 n+2}\right)+d\left(S(x), T\left(x_{2 n+1}\right)\right) .
\end{aligned}
$$

By (c), 


$$
\begin{aligned}
d\left(S(x), T\left(x_{2 n+1}\right)\right) \leqq & a_{1} d(x, S(x))+a_{2} d\left(x_{2 n+1}, x_{2 n+2}\right)+a_{3} d\left(x, x_{2 n+2}\right) \\
& +a_{4} d\left(x_{2 n+1}, S(x)\right)+a_{5} d\left(x, x_{2 n+1}\right) .
\end{aligned}
$$

Combining (7) and (8) and letting $n$ tend to infinity, we obtain

$$
d(x, S(x)) \leqq\left(a_{1}+a_{4}\right) d(x, S(x)) \text {. }
$$

Since $a_{1}+a_{4}<1, S(x)=x$. Similarly $T(x)=x$. Let $y$ be a fixed point of $T$. Then from $d(x, y)=d(S(x), T(y))$ and (c), we obtain

$$
d(x, y) \leqq\left(a_{3}+a_{4}+a_{5}\right) d(x, y) .
$$

Since $a_{3}+a_{4}+a_{5}<1, d(x, y)=0$. So $T$ has a unique fixed point. Similarly, $S$ has a unque fixed point.

When $a_{3}=a_{4}=a_{5}=0, S=T$ and $T$ is continuous (or even $x \rightarrow d(x, T(x))$ is lower semicontinuous) on $X$, Theorem 1 can be obtained by an earlier result of the author [11, Theorem 1].

From the proof of Theorem 1, we know that $S, T$ still have a common fixed point if conditions (a), (b) are replaced by the following conditions:

$$
\begin{gathered}
\left(a_{1}+a_{3}+a_{5}\right)\left(a_{2}+a_{4}+a_{5}\right)<\left(1-a_{2}-a_{3}\right)\left(1-a_{1}-a_{4}\right), \\
a_{1}+a_{4}<1 .
\end{gathered}
$$

If in addition,

$$
a_{3}+a_{4}+a_{5}<1
$$

then the common fixed point of $S, T$ is the unique fixed point of $S$ (and T). Note that conditions (a) and (b) imply (9), but (a) alone does not. Indeed, for any $a_{1}, a_{2}, a_{5}$ in $[0, \infty)$ with $a_{1} \neq a_{2}$ and $a_{1}+a_{2}+a_{5}<1$, we can always find $a_{3}, a_{4}$ in $[0, \infty)$ such that (a) holds but (9) does not. This can be seen by considering the affine function $f$ :

$$
f(x, y)=\left(1-a_{2}-x\right)\left(1-a_{1}-y\right)-\left(a_{1}+x+a_{5}\right)\left(a_{2}+y+a_{5}\right)
$$

defined on the compact convex set

$$
K=\left\{(x, y) \in[0,1] \times[0,1]: a_{1}+a_{2}+x+y+a_{5} \leqq 1\right\} .
$$

$f$ takes its minimum value at one of the extreme points of $K$. With some computation, we conclude that

$$
\min f(K)=-\left|a_{1}-a_{2}\right|\left(1-a_{1}-a_{2}-a_{5}\right) .
$$

Since $a_{1}+a_{2}+a_{5}>1, \min f(K)<0$ if and only if $a_{1} \neq a_{2}$. Thus if $a_{1} \neq a_{2}$, then by continuity of $f$, there exists a point $\left(a_{3}, a_{4}\right)$ in 


$$
K \backslash\left\{(x, y) \in K: a_{1}+a_{2}+x+y+a_{5}=1\right\}
$$

such that $f\left(a_{3}, a_{4}\right)<0$.

CoRollary 1. R. Kannan [7, Theorem 1]. Let $S$ be a mapping of a complete metric space $(X, d)$ into itself. Suppose that there exists a number $r$ in $[0,1 / 2)$ such that

$$
d(S(x), S(y)) \leqq r(d(x+S(x))+d(y, S(y)))
$$

for all $x, y$ in $X$. Then $S$ has a unique fixed point.

Corollary 2. P. Srivastava and V. K. Gupta [10, Theorem 1]. Let $S, T$ be mappings of a complete metric space $(X, d)$ into itself. Suppose that there exists nonnegative real numbers $a_{1}, a_{2}$ such that

$$
a_{1}+a_{2}<1
$$

and

$$
\begin{array}{r}
d(S(x), T(y)) \leqq a_{1} d(x, S(x))+a_{2} d(y, T(y)) \\
\text { for all } x, y \text { in } X .
\end{array}
$$

Then S, T have a unique common fixed point.

Srivastava and Gupta stated the above result in a more general form with $S, T$ replaced by $S^{p}, T^{q}$ for some positive integers $p, q$. Since the unique fixed point of $S^{p}$ (similarly $T^{q}$ ) is the unique fixed point of $S$, this result is equivalent to Corollary 2 .

For Corollaries 1 and 2, we have the following related result.

Proposition. Let $S, T$ be self-maps of a nonempty complete metric space $(X, d)$. Suppose that there exist nonnegative real numbers $a_{1}$, $a_{2}$ such that $a_{1}+a_{2}<1$ and

$$
d(S(x), T(y)) \leqq a_{1} d(x, S(x))+a_{2} d(y, T(y)), \quad x, y \in X .
$$

Then either $(*)$ is true when all of its $S$ are replaced by $T$ or $\left(^{*}\right)$ is true when all of its $T$ are replaced by $S$.

The following example proves that our result is actually more general than that of Srivastava and Gupta.

ExAmple. Let $X=\{1,2,3\}$. Let $d$ be the metric for $X$ determined by

$$
d(1,2)=1, d(2,3)=\frac{4}{7}, \quad d(1,3)=\frac{5}{7}
$$


Let $S, T$ be the function on $X$ such that

$$
\begin{aligned}
& S(1)=S(2)=S(3)=1 ; \\
& T(1)=T(3)=1, \quad T(2)=3 .
\end{aligned}
$$

Let $a_{1}=0, a_{2}=0, a_{3}=0, a_{4}=5 / 7, a_{5}=0$. Then the conditions of Theorem 1 are satisfied. However, no nonnegative real numbers $a_{1}, a_{2}, a_{3}, a_{5}$ can be chosen such that $a_{1}+a_{2}+a_{3}+a_{5}<1$ and for $x, y \in X$,

$$
d(S(x), T(y)) \leqq a_{1} d(x, S(x))+a_{2} d(y, T(y))+a_{3} d(x, T(y))+a_{5} d(x, y) .
$$

For if there exist such $a_{1}, a_{2}, a_{3}, a_{5}$, then

$$
d(S(3), T(2)) \leqq a_{1} d(3, S(3))+a_{2} d(2, T(2))+a_{3} d(3, T(2))+a_{5} d(3,2) .
$$

So

$$
\frac{5}{7} \leqq \frac{5 a_{1}}{7}+\frac{4 a_{2}}{7}+\frac{4 a_{5}}{7} \leqq \frac{5}{7}\left(a_{1}+a_{2}+a_{5}\right)<\frac{5}{7},
$$

a contradiction.

Corollary 3. G. Hardy and T. Rogers [5, Theorem 1]. Let $S$ be a mapping of a nonempty complete metric space $(X, d)$ into itself. Suppose that there exist nonnegative real numbers $a_{1}, a_{2}, a_{3}, a_{4}, a_{5}$ such that

$$
a_{1}+a_{2}+a_{3}+a_{4}+a_{5}<1
$$

and

$$
\begin{gathered}
d(S(x), S(y)) \leqq a_{1} d\left(x, S(x)+a_{2} d(y, S(y))+a_{3} d(x, S(y))\right. \\
+a_{4} d(y, S(x))+a_{5} d(x, y)
\end{gathered}
$$

for all $x, y$ in $X$.

Then $S$ has a unique fixed point.

Note that in the above case, we may without loss of generality assume that $a_{1}=a_{2}, a_{3}=a_{4}$ (replace $a_{1}, a_{2}, a_{3}, a_{4}, a_{5}$ respectively by

$$
\frac{a_{1}+a_{2}}{2}, \frac{a_{1}+a_{2}}{2}, \frac{a_{3}+a_{4}}{2}, \frac{a_{3}+a_{4}}{2}, a_{5}
$$

if necessary). So the above result follows from Theorem 1. The above example shows that there is no such symmetry $\left(a_{1}=a_{2}, a_{3}=a_{4}\right)$ for the general case. Indeed, we cannot even assume $a_{3}=a_{4}$. For if $a_{3}=a_{4}$, then for the above example, we have 


$$
\begin{aligned}
\frac{5}{7}=d(S(3), T(3)) & \leqq \frac{5}{7} a_{1}+\frac{4}{7} a_{2}+a_{4}+\frac{4}{7} a_{5} . \\
& =\frac{5}{7} a_{1}+\frac{4}{7} a_{2}+\frac{1}{2} a_{3}+\frac{1}{2} a_{4}+\frac{4}{7} a_{5} \\
& <\frac{5}{7}\left(a_{1}+a_{2}+a_{3}+a_{4}+a_{5}\right)<\frac{5}{7},
\end{aligned}
$$

a contradiction.

2. Extensions and some ralated results. The following result generalizes Theorem 1. Its proof is different from the one we gave for Theorem 1.

THEOREM 2. Let $S, T$ be functions on a nonempty complete metric space $(X, d)$. Suppose that there exist decreasing functions $\alpha_{1}, \alpha_{2}, \alpha_{3}, \alpha_{4}, \alpha_{5}$ of $(0, \infty)$ into $[0,1)$ such that

(a) $\sum_{i=1}^{5} \alpha_{i}<1$;

(b) $\alpha_{1}=\alpha_{2}$ or $\alpha_{3}=\alpha_{4}$;

(c) $\lim _{t \downarrow 0}\left(\alpha_{2}+\alpha_{3}\right)<1$ and $\lim _{t \downarrow 0}\left(\alpha_{1}+\alpha_{4}\right)<1$;

(d) for any distinct $x, y$ in $X$,

$$
\begin{aligned}
d(S(x), T(y)) \leqq & a_{1} d(x, S(x))+a_{2} d(y, T(y))+a_{3} d(x, T(y)) \\
& +a_{4} d(y, S(x))+a_{5} d(x, y)
\end{aligned}
$$

where $a_{i}=\alpha_{i}(d(x, y))$.

Then at least one of $S, T$ has a fixed point. If both $S$ and $T$ have fixed points, then each of $S, T$ has a unique fixed point and these two fixed points coincide.

Proof. Let $x_{0} \in X$. Define for each $n=0,1,2, \cdots$,

$$
x_{2 n+1}=S\left(x_{2 n}\right), \quad x_{2 n+2}=T\left(x_{2 n+1}\right), \quad b_{n}=d\left(x_{n}, x_{n+1}\right) .
$$

We may assume that $b_{n}>0$ for each $n$, for otherwise some $x_{n}$ is a fixed point of $S$ or $T$. Let

$$
\begin{array}{ll}
r(t)=\frac{\alpha_{1}(t)+\alpha_{3}(t)+\alpha_{5}(t)}{1-\alpha_{2}(t)-\alpha_{3}(t)}, & t>0, \\
s(t)=\frac{\alpha_{2}(t)+\alpha_{4}(t)+\alpha_{5}(t)}{1-\alpha_{1}(t)-\alpha_{4}(t)}, & t>0 .
\end{array}
$$

Then $r, s$ are decreasing. From (a) and (c), the limits

$$
r_{0}=\lim _{t \downarrow 0} r(t), \quad s_{0}=\lim _{t \downarrow 0} s(t)
$$

are nonnegative real numbers. Let 


$$
f(t)=r(t) s(t),
$$

Then $f$ is decreasing and $f(t)<1$ for each $t>0$. As in the proof of Theorem 1 , we have for each $n=0,1,2, \cdots$,

$$
\begin{aligned}
& b_{2 n+1} \leqq r\left(b_{2 n}\right) b_{2 n}, \\
& b_{2 n+2} \leqq s\left(b_{2 n+1}\right) b_{2 n+1} .
\end{aligned}
$$

Let $n$ be given. Then

$$
\begin{aligned}
& b_{2 n+3} \leqq r\left(b_{2 n+2}\right) s\left(b_{2 n+1}\right) b_{2 n+1}, \\
& b_{2 n+2} \leqq s\left(b_{2 n+1}\right) r\left(b_{2 n}\right) b_{2 n} .
\end{aligned}
$$

Since $r, s$ are decreasing,

$$
\begin{aligned}
& b_{2 n+3} \leqq f\left(\min \left\{b_{2 n+2}, b_{2 n+1}\right\}\right) b_{2 n+1}, \\
& b_{2 n+2} \leqq f\left(\min \left\{b_{2 n+1}, b_{2 n}\right\}\right) b_{2 n} .
\end{aligned}
$$

Since $f(t)<1$ for each $t>0,\left\{b_{2 n+1}\right\},\left\{b_{2 n}\right\}$ are decreasing sequences. So $\left\{b_{2 n+1}\right\},\left\{b_{2 n}\right\}$ converge respectively to some points $c_{1}, c_{2}$. We shall prove that $c_{1}=0, c_{2}=0$. From (12) and (13),

$$
c_{1} \leqq r_{0} c_{2}, \quad c_{2} \leqq s_{0} c_{1} .
$$

So either both $c_{1}, c_{2}$ are zero or both $c_{1}, c_{2}$ are not zero. Suppose to the contrary that $c_{1} \neq 0, c_{2} \neq 0$. Then from (16) and (17),

$$
b_{n+2} \leqq f\left(\min \left\{c_{1}, c_{2}\right\}\right) b_{n}, \quad n=0,1,2, \cdots \text {. }
$$

By induction,

$$
b_{2 n} \leqq\left(f\left(\min \left\{c_{1}, c_{2}\right\}\right)\right)^{n} b_{0} \quad n=0,1,2, \cdots .
$$

So $c_{2}=0$, a contradiction. Therefore, $c_{1}=c_{2}=0$. This proves that $\left\{b_{n}\right\}$ converges to 0 .

Now we shall prove that $\left\{x_{n}\right\}$ is Cauchy. Suppose not. Then there exist $\varepsilon \in(0, \infty)$ and sequences $\{p(n)\},\{q(n)\}$ such that for each $n \geqq 0$,

$$
\begin{aligned}
& p(n)>q(n)>n, \\
& d\left(x_{p(n)}, x_{q(n)}\right) \geqq \varepsilon,
\end{aligned}
$$

and (by the well-ordering principle),

$$
d\left(x_{p(n)-1}, x_{q(n)}\right)<\varepsilon .
$$

Let $n \geqq 0$ be given, $c_{n}=d\left(x_{p(n)}, x_{q(n)}\right)$. Then 


$$
\begin{aligned}
\varepsilon & \leqq c_{n} \\
& \leqq d\left(x_{p(n)}, x_{p(n)-1}\right)+d\left(x_{p(n)-1}, x_{q(n)}\right)<b_{p(n)-1}+\varepsilon
\end{aligned}
$$

From $c_{1}=c_{2}=0$, we conclude that $\left\{c_{n}\right\}$ converges to $\varepsilon$ from the right. Let

$$
\begin{aligned}
& I_{1}=\{n: p(n), q(n) \text { are odd }\}, \\
& I_{2}=\{n: p(n) \text { is odd, } q(n) \text { is even }\} . \\
& I_{3}=\{n: p(n) \text { is even, } q(n) \text { is odd }\}, \\
& I_{4}=\{n: p(n), q(n) \text { are even }\} .
\end{aligned}
$$

Then at least one of $I_{1}, I_{2}, I_{3}, I_{4}$ is infinite. Suppose first that $I_{1}$ is infinite. Let

$$
d_{n}=d\left(x_{p(n)-1}, x_{q(n)}\right), \quad n=0,1,2, \cdots .
$$

Since $\left\{c_{n}\right\}$ converges to $\varepsilon$ and $\left\{b_{n}\right\}$ converges to 0 , we conclude from (22) that $\left\{d_{n}\right\}$ converges to $\varepsilon$ from the left. Thus

$$
J_{1}=\left\{n \in I_{1}: x_{p(n)-1} \neq x_{q(n)}\right\}
$$

is infinite. Let $n \in J_{1}, u_{n}=d\left(x_{p(n)-1}, x_{q(n)+1}\right)$. Then

$$
\begin{aligned}
c_{n}=d\left(x_{p(n)}, x_{q(n)}\right) & \leqq d\left(x_{p(n)}, x_{q(n)+1}\right)+d\left(x_{q(n)+1}, x_{q(n)}\right) \\
& \leqq d\left(S\left(x_{p(n)-1}\right), T\left(x_{q(n)}\right)\right)+b_{q(n)} .
\end{aligned}
$$

From $(d)$,

$$
\begin{aligned}
d\left(S\left(x_{p(n)-1}\right), T\left(x_{q(n)}\right)\right) \leqq & \alpha_{1}\left(d_{n}\right) b_{p(n)-1}+\alpha_{2}\left(d_{n}\right) b_{q(n)}+\alpha_{3}\left(d_{n}\right) u_{n} \\
& +\alpha_{4}\left(d_{n}\right) c_{n}+\alpha_{5}\left(d_{n}\right) d_{n} .
\end{aligned}
$$

From (24) and (25),

$$
\begin{aligned}
c_{n} \leqq & \alpha_{1}\left(d_{n}\right) b_{p(n)-1}+\alpha_{2}\left(d_{n}\right) b_{q(n)}+\alpha_{3}\left(d_{n}\right) u_{n}+\alpha_{4}\left(d_{n}\right) c_{n} \\
& +\alpha_{5}\left(d_{n}\right) d_{n}+b_{q(n)} .
\end{aligned}
$$

Without loss of generality, we may assume that each $\alpha_{i}$ is continuous from the left, for we can replace the $\alpha_{i}$ 's by

$$
\beta_{i}(t)=\lim _{s \uparrow t} \alpha_{i}(s), \quad t>0, \quad i=1,2,3,4,5
$$

and conditions (a), (b), (c), and (d) still hold. Thus

$$
\lim _{n \rightarrow \infty} \alpha_{i}\left(d_{n}\right)=\alpha_{i}(\varepsilon), \quad i=1,2,3,4,5 \text {. }
$$

So from (26),

$$
\varepsilon \leqq\left(\alpha_{3}(\varepsilon)+\alpha_{4}(\varepsilon)+\alpha_{5}(\varepsilon)\right) \varepsilon<\varepsilon,
$$


a contradiction. Now suppose that $I_{2}$ is infinite. By a similar argument, $J_{2}=\left\{n \in I_{2}: x_{p(n)-1} \neq x_{q(n)-1}\right\}$ is infinite. Let $n \in J_{2}$,

$$
v_{n}=d\left(x_{p(n)-1}, x_{q(n)-1}\right), \quad w_{n}=d\left(x_{p(n)}, x_{q(n)-1}\right) \text {. }
$$

Then

$$
\begin{aligned}
c_{n} & =d\left(S\left(x_{p(n)-1}\right), T\left(x_{q(n)-1}\right)\right) \\
& \leqq \alpha_{1}\left(v_{n}\right) b_{p(n)-1}+\alpha_{2}\left(v_{n}\right) b_{q(n)-1}+\alpha_{3}\left(v_{n}\right) d_{n}+\alpha_{4}\left(v_{n}\right) w_{n}+\alpha_{5}\left(v_{n}\right) v_{n} .
\end{aligned}
$$

Since $\left\{v_{n}\right\}$ converges to $\varepsilon$ (not necessarily from the left or right), we obtain the same contradiction from (27). The other two cases are similar to the above two except the roles of $S, T$ interchange. Hence $\left\{x_{n}\right\}$ is Cauchy. By completeness, $\left\{x_{n}\right\}$ converges to a point $x$ in $X$. Since $b_{n}>0$ for each $n, J=\left\{n: x \neq x_{2 n+1}\right\}$ or $K=\left\{n: x \neq x_{2 n}\right\}$ is infinite. Suppose that $K$ is infinite. Let $n \in K$,

$$
l_{n}=d\left(x, x_{2 n}\right), \quad h_{n}=d\left(x, x_{2 n+1}\right) .
$$

Then

$$
\begin{aligned}
d(x, T(x)) \leqq & d\left(x, x_{2 n+1}\right)+d\left(x_{2 n+1}, T(x)\right) \\
= & h_{n}+d\left(S\left(x_{2 n}\right), T(x)\right) \\
\leqq & h_{n}+\alpha_{1}\left(l_{n}\right) b_{2 n}+\alpha_{2}\left(l_{n}\right) d(x, T(x))+\alpha_{3}\left(l_{n}\right) d\left(x_{2 n}, T(x)\right) \\
& +\alpha_{4}\left(l_{n}\right) h_{n}+\alpha_{5}\left(l_{n}\right) l_{n} \\
\leqq & h_{n}+\alpha_{1}\left(l_{n}\right) b_{2 n}+\alpha_{2}\left(l_{n}\right) d(x, T(x))+\alpha_{3}\left(l_{n}\right)\left[l_{n}+d(x, T(x))\right] \\
& +\alpha_{4}\left(l_{n}\right) h_{n}+\alpha_{5}\left(l_{n}\right) l_{n} .
\end{aligned}
$$

So

$$
\begin{aligned}
d(x, T(x)) \leqq \frac{1+\alpha_{4}\left(l_{n}\right)}{1-\alpha_{2}\left(l_{n}\right)-\alpha_{3}\left(l_{n}\right)} h_{n} & +\frac{\alpha_{3}\left(l_{n}\right)+\alpha_{5}\left(l_{n}\right)}{1-\alpha_{2}\left(l_{n}\right)-\alpha_{3}\left(l_{n}\right)} l_{n} \\
& +\frac{\alpha_{1}\left(l_{n}\right)}{1-\alpha_{2}\left(l_{n}\right)-\alpha_{3}\left(l_{n}\right)} b_{2 n} .
\end{aligned}
$$

From (a) and (c), the sequences

$$
\frac{1+\alpha_{4}\left(l_{n}\right)}{1-\alpha_{2}\left(l_{n}\right)-\alpha_{3}\left(l_{n}\right)}, \frac{\alpha_{3}\left(l_{n}\right)+\alpha_{5}\left(l_{n}\right)}{1-\alpha_{2}\left(l_{n}\right)-\alpha_{3}\left(l_{n}\right)}, \frac{\alpha_{1}\left(l_{n}\right)}{1-\alpha_{2}\left(l_{n}\right)-\alpha_{3}\left(l_{n}\right)}
$$

are bounded. So from (28), $T(x)=x$. Similarly, $S(x)=x$ if $J$ is infinite. Hence $S$ or $T$ has a fixed point.

The following result follows easily from Theorem 2.

THEOREM 3. With the conditions of Theorem 2, if further,

$$
d(S(x), T(x)) \leqq \alpha[d(x, S(x))+d(x, T(x))], \quad x \in X
$$


for some $\alpha \in[0,1)$, then each of $S, T$ has a unique fixed point and these two fixed points coincide.

We remark that the conditions of Theorem 1 imply the conditions of Theorem 3. Also, G. Hardy and T. Rogers [5, Theorem 2] gave a different proof for the case $S=T$. Their proof cannot be modified for the general case. To see that the conclusion of Theorem 2 is best possible, we note that if $X=\{0,1\}$ with the usual distance and if $S, T$ are two distinct functions of $X$ onto $X$, then $S, T$ satisfy the conditions of Theorem 2 (and Theorem 3 with $\alpha=1$ ), but one has two fixed points and the other has none.

THEOREM 4. Let $(X, d)$ be a nonempty compact metric space. Let $S, T$ be functions of $X$ into itself. Suppose that $S$ or $T$ is continuous. Suppose further that there exist nonnegative real-valued decreasing functions $\alpha_{1}, \alpha_{2}, \alpha_{3}, \alpha_{4}, \alpha_{5}$ on $(0, \infty)$ such that

(a) $\alpha_{1}+\alpha_{2}+\alpha_{3}+\alpha_{4}+\alpha_{5} \leqq 1$,

(b) $\alpha_{1}=\alpha_{2}$ and $\alpha_{3}=\alpha_{4}$,

(c) for any distinct $x, y$ in $X$,

$$
\begin{gathered}
d(S(x), T(y))<a_{1} d(x, S(x))+a_{2} d(y, T(y))+a_{3} d(x, T(y))+ \\
a_{4} d(y, S(x))+a_{5} d(x, y),
\end{gathered}
$$

where $a_{i}=\alpha_{i}(d(x, y))$.

Then $S$ or $T$ has a fixed point. If both $S$ and $T$ have fixed points, then each of $S$ and $T$ has a unique fixed point and these two fixed points coincide.

Proof. By symmetry, we may assume that $S$ is continuous. Let $f$ be the function on $X$ such that

$$
f(x)=d(x, S(x)), \quad x \in X .
$$

Then $f$ is continuous (we merely need the fact that $f$ is lower semicontinuous) on $X$. So $f$ takes its minimum value at some $x_{0}$ in $X$. We claim that $x_{0}$ is a fixed point of $S$ or $S\left(x_{0}\right)$ is a fixed point of $T$. Suppose not. Let

$$
\begin{array}{ll}
x_{1}=S\left(x_{0}\right), & x_{2}=T\left(x_{1}\right), \quad x_{3}=S\left(x_{2}\right), \\
b_{0}=d\left(x_{0}, x_{1}\right), & b_{1}=d\left(x_{2}, x_{3}\right), \quad b_{2}=d\left(x_{2}, x_{3}\right) .
\end{array}
$$

Then $b_{0}>0, b_{1}>0$. From (c), we can prove that

$$
\left(1-\alpha_{2}\left(b_{0}\right)-\alpha_{3}\left(b_{0}\right)\right) b_{1}<\left(\alpha_{1}\left(b_{0}\right)+\alpha_{3}\left(b_{0}\right)+\alpha_{5}\left(b_{0}\right)\right) b_{0} .
$$




$$
p(t)=1-\alpha_{2}(t)-\alpha_{3}(t), \quad q(t)=\alpha_{1}(t)+\alpha_{3}(t)+\alpha_{5}(t), \quad t>0 .
$$

From (a) and (b), $p\left(b_{0}\right)>0$. So

$$
b_{1}<\frac{q\left(b_{0}\right)}{p\left(b_{0}\right)} b_{0}
$$

Similarly,

$$
b_{2}<\frac{v\left(b_{1}\right)}{u\left(b_{1}\right)} b_{1}
$$

where

$$
u(t)=1-\alpha_{1}(t)-\alpha_{4}(t), v(t)=\alpha_{2}(t)+\alpha_{4}(t)+\alpha_{5}(t), \quad t>0 .
$$

From (30) and (31),

$$
b_{2}<\frac{v\left(b_{1}\right)}{u\left(b_{1}\right)} \frac{q\left(b_{0}\right)}{p\left(b_{0}\right)} b_{0}
$$

It suffices to prove that $\left(v\left(b_{1}\right) q\left(b_{0}\right) / u\left(b_{1}\right) p\left(b_{0}\right)\right)<1$, for then, $b_{2}<b_{0}$, a contradiction to the minimality of $b_{0}$. Let $b=\min \left\{b_{0}, b_{1}\right\}$. Then

$$
v\left(b_{1}\right) q\left(b_{0}\right)-u\left(b_{1}\right) p\left(b_{0}\right) \leqq v(b) q(b)-u(b) p(b)<0
$$

if $\alpha_{1}=\alpha_{2}$ and $\alpha_{3}=\alpha_{4}$. So $S$ or $T$ has a fixed point. Now suppose that $x$ is a fixed point of $S$ and $y$ is a fixed point of $T$. Then $x=y$, otherwise, from (c),

$$
d(x, y)=d(S(x), T(y))<d(x, y),
$$

a contradiction.

The following result is stated without proof.

THEOREM 5. Let $(X, d)$ be complete metric space. Let $\left\{S_{n}\right\},\left\{T_{n}\right\}$ be sequence of functions of $X$ into $X$ which converge pointwise to $S, T$ respectively. Suppose that the pairs $\left(S_{n}, T_{n}\right)$ satisfy the conditions of Theorem 3 with the same $\alpha_{1}, \alpha_{2}, \alpha_{3}, \alpha_{4}, \alpha_{5}$. Then $S, T$ have $a$ unique common fixed point $x$ and $x$ is the limit of the sequence $\left\{x_{n}\right\}$ of the fixed points $x_{n}$ of $S_{n}$.

THEOREM 6. Let $(X, d)$ be a nonempty compact metric space. Let $\left\{S_{n}\right\},\left\{T_{n}\right\}$ be sequences of functions of $X$ into itself which converge pointwise to the functions $S, T$ on $X$ respectively. Suppose that for each $n$, there exist decreasing functions $\alpha_{1}^{n}, \alpha_{2}^{n}, \alpha_{3}^{n}, \alpha_{4}^{n}, \alpha_{5}^{n}$ of $(0, \infty)$ into $[0, \infty)$ such that 
(a) $\alpha_{1}^{n}+\alpha_{2}^{n}+\alpha_{3}^{n}+\alpha_{4}^{n}+\alpha_{3}^{n} \leqq 1$,

(b) $\alpha_{1}^{n}=\alpha_{2}^{n}$ and $\alpha_{3}^{n}=\alpha_{4}^{n}$,

(c) for any distinct $x, y$ in $X$,

$$
\begin{aligned}
d\left(S_{n}(x), T_{n}(y)\right)< & a_{1}^{n} d\left(x, S_{n}(x)\right)+a_{2}^{n} d\left(y, T_{n}(y)\right)+a_{3}^{n} d\left(x, T_{n}(y)\right) \\
& +a_{4}^{n} d\left(y, S_{n}(x)\right)+a_{5}^{n} d(x, y),
\end{aligned}
$$

where

$$
a_{i}^{n}=\alpha_{i}^{n}(d(x, y)) .
$$

Then $S$ or $T$ has a fixed point. Indeed, every cluster point of a sequence $\left\{x_{n}\right\}$ of fixed points $x_{n}$ of $S_{n}$ or $T_{n}$ is a fixed point of $S$ or $T$.

Proof. By Theorem 4, for each $n$, either $S_{n}$ or $T_{n}$ has a fixed point. By symmetry, we may assume that $S_{n}$ has a fixed point for infinitely many of $n$ 's. So there is a subsequence $\left\{S_{n(k)}\right\}$ of $\left\{S_{n}\right\}$ such that each $S_{n(k)}$ has a fixed point, say $x_{k}$. By compactness, we may (by taking a subsequence) assume that $\left\{x_{k}\right\}$ converges to some $x$ in $X$. We shall prove that $x$ is a fixed point of $S$ or $T$. If $x_{k} \neq x$ for only finitely many of $k$ 's, then

$$
\begin{aligned}
S(x) & =\lim _{k \rightarrow \infty} S_{n(k)}(x) \\
& =\lim _{k \rightarrow \infty} S_{n(k)}\left(x_{k}\right) \\
& =\lim _{k \rightarrow \infty} x_{k} \\
& =x .
\end{aligned}
$$

So we may assume that $x_{k} \neq x$ for infinitely many of $k$ 's. By taking a subsequence, we may assume that $x_{k} \neq x$ for each $k$. Let $k \geqq 1$ and $b_{k}=d\left(x, x_{k}\right)$. Then

$$
\begin{aligned}
d(x, T(x)) & \leqq d\left(x, x_{k}\right)+d\left(x_{k}, T_{n(k)}(x)\right)+d\left(T_{n(k)}(x), T(x)\right) \\
& =d\left(x, x_{k}\right)+d\left(S_{n(k)}\left(x_{k}\right), T_{n(k)}(x)\right)+d\left(T_{n(k)}(x), T(x)\right) .
\end{aligned}
$$

From (c),

$$
\begin{aligned}
d\left(S_{n(k)}\left(x_{k}\right), T_{n(k)}(x)\right)< & \alpha_{2}^{k}\left(b_{k}\right) d\left(x, T_{n(k)}(x)\right)+\alpha_{3}^{k}\left(b_{k}\right) d\left(x_{k}, T_{n(k)}(x)\right) \\
& +\alpha_{4}^{k}\left(b_{k}\right) d\left(x, x_{k}\right)+\alpha_{5}^{k}\left(b_{k}\right) b_{k} .
\end{aligned}
$$

Combining (33) and (34) and letting $k$ tend to the infinity, we have

$$
\begin{aligned}
d(x, T(x)) & \leqq \limsup _{k \rightarrow \infty}\left(\alpha_{2}^{k}\left(b_{k}\right)+\alpha_{3}^{k}\left(b_{k}\right)\right) d(x, T(x)) \\
& \leqq \limsup _{k \rightarrow \infty} \lim _{t \downarrow 0}\left(\alpha_{2}^{k}(t)+\alpha_{3}^{k}(t)\right) d(x, T(x)) .
\end{aligned}
$$

From $(\mathrm{b}), \alpha_{2}^{k}(t)+\alpha_{3}^{k}(t) \leqq 1 / 2$ for each $t>0, k=1,2, \cdots$. So 


$$
\limsup _{k \rightarrow \infty} \lim _{t \downarrow 0}\left(\alpha_{2}^{k}(t)+\alpha_{3}^{k}(t)\right) \leqq \frac{1}{2} .
$$

From (35) and (36), we conclude that $T(x)=x$.

From the proof, we know that the same conclusion holds if in Theorem 6, we replace (b) by the following weaker conditions:

$$
\begin{gathered}
\alpha_{1}^{n}=\alpha_{2}^{n} \text { or } \alpha_{3}^{n}=\alpha_{4}^{n}, \\
\underset{k \rightarrow \infty}{\lim \sup } \lim _{t \downarrow 0}\left(\alpha_{2}^{k}(t)+\alpha_{3}^{k}(t)\right)<1,
\end{gathered}
$$

and

$$
\limsup _{k \rightarrow \infty} \lim _{t \downarrow 0}\left(\alpha_{\llcorner}^{n}(t)+\alpha_{4}^{n}(t)\right)<1 .
$$

We note that, unlike Theorem 5, S, $T$ in Theorem 6 need not satisfy the condition required for the pairs $\left(S_{n}, T_{n}\right)$.

Theorem 7. Let $(X, d)$ be a nonempty compact metric space. Let $\left\{S_{n}\right\}$ be a sequence of functions of $X$ into itself which converges pointwise to some function $S$ on $X$. Suppose that for each $n$, there exist decreasing functions $\alpha_{1}^{n}, \alpha_{2}^{n}, \alpha_{3}^{n}, \alpha_{4}^{n}, \alpha_{5}^{n}$ of $(0, \infty)$ into $[0, \infty)$ such that

(a) $\alpha_{1}^{n}+\alpha_{2}^{n}+\alpha_{3}^{n}+\alpha_{4}^{n}+\alpha_{5}^{n} \leqq 1$,

(b) for any distinct $x, y$ in $X$,

$$
\begin{aligned}
d\left(S_{n}(x), S_{n}(y)\right)< & a_{1} d\left(x, S_{n}(x)\right)+a_{2} d\left(y, S_{n}(y)\right)+a_{3} d\left(x, S_{n}(y)\right) \\
& +a_{4} d\left(y, S_{n}(x)\right)+a_{5} d(x, y)
\end{aligned}
$$

where

$$
a_{i}=\alpha_{i}(d(x, y)) .
$$

Then $S$ has a fixed point. Indeed, every cluster point of the sequence of fixed points of $S_{n}$ is a fixed point of $S$.

The above result follows from Theorem 6 by averaging two applications of condition (b).

We shall now give a simple example to show that the conclusion of Theorem 7 is best possible. Let $X$ be a star-shaped [4] compact subset of a normed linear space $B$. Then there exists a point $z$ in $X$ such that for any $y$ in $X$, the line segment

$$
\{t z+(1-t) y: t \in[0,1]\}
$$

is contained in $X$. For each $n$, let

$$
S_{n}(x)=\frac{1}{n} z+\left(1-\frac{1}{n}\right) x, \quad x \in X .
$$


Then $\left\{S_{n}\right\}$ is a sequence of mappings of $X$ into $X$ which satisfy the conditions of Theorem 7. $\left\{S_{n}\right\}$ converges pointwise to the identity function $S$ on $X$. Every point of $X$ is a fixed point of $S$. So unlike Theorem 5, it is too much to ask that $S$ in Theorem 7 has a unique fixed point.

\section{REFERENCES}

1. W. M. Boyce, Commuting functions with no common fixed point, Trans. Amer. Math. Soc., 137 (1969), 77-92.

2. - $\Gamma$-compact mappings on an interval and fixed points, Trans. Amer. Math. Soc., 160 (1971), 87-102.

3. M. Edelstein, On fixed and periodic points under contractive mappings, J. London Math. Soc., 37 (1962), 74-79.

4. B. Halpern, The kernel of a starshaped subset of the plane, Proc. Amer. Math. Soc., 23 (1969), 692-696.

5. G. Hardy and T. Rogers, A generalization of a fixed point theorem of Reich, (to appear).

6. J. P. Huneke, On common fixed point of commuting continuous functions on an interval, Trans. Amer. Math. Soc., 139 (1969), 371-381.

7. R. Kannan, Some results on fixed points-II, Amer. Math. Monthly, 76 (1969), 405408.

8. E. Rakotch, $A$ note on contractive mappings, Proc. Amer. Math. Soc., 13 (1962), 469-465.

9. S. Reich, Some remarks concerning contraction mappings, Canad. Math. Bull. 14 (1971), 121-124.

10. P. Srivastava and V. K. Gupta, A note on common fixed points, Yokohama Math. J., XIX (1971), 91-95.

11. Chi Song Wong, Fixed point theorems for nonexpansive mappings, J. Math. Anal. Appl., 37 (1972), 142-150.

Received June 13, 1972. This research was partially supported by the National Research Council of Canada Grant A8518 and a grant from the Canadian Mathematical Congress. It was prepared while the author was at the Summer Research Institute, University of Alberta.

UNIVERSITY OF WINDSOR 


\section{PACIFIC JOURNAL OF MATHEMATICS}

\section{EDITORS}

RICHARD ARENS (Managing Editor)

University of California

Los Angeles, California 90024

R. A. Beaumont

University of Washington

Seattle, Washington 98105
J. DUGUNDJI*

Department of Mathematics

University of Southern California

Los Angeles, California 90007

D. Gilbarg and J. Milgram

Stanford University

Stanford, California 94305

\section{ASSOCIATE EDITORS}
E. F. BECKENBACH
B. H. NeumanN
F. WOLF
K. YosHIDA

\section{SUPPORTING INSTITUTIONS}

UNIVERSITY OF BRITISH COLUMBIA
CALIFORNIA INSTITUTE OF TECHNOLOGY
UNIVERSITY OF CALIFORNIA
MONTANA STATE UNIVERSITY
UNIVERSITY OF NEVADA
NEW MEXICO STATE UNIVERSITY
OREGON STATE UNIVERSITY
UNIVERSITY OF OREGON
OSAKA UNIVERSITY

UNIVERSITY OF BRITISH COLUMBIA

UNIVERSITY OF CALIFORNIA

MONTANA STATE UNIVERSITY

UNIVERSITY OF NEVADA

OREGON STATE UNIVERSITY

OSAKA UNIVERSITY
UNIVERSITY OF SOUTHERN CALIFORNIA

STANFORD UNIVERSITY

UNIVERSITY OF TOKYO

UNIVERSITY OF UTAH

WASHINGTON STATE UNIVERSITY

UNIVERSITY OF WASHINGTON

\section{AMERICAN MATHEMATICAL SOCIETY} NAVAL WEAPONS CENTER

* C. R. DePrima California Institute of Technology, Pasadena, CA 91109, will replace J. Dugundji until August 1974. 


\section{Pacific Journal of Mathematics}

\section{Vol. 48, No. $1 \quad$ March, 1973}

Jan Aarts and David John Lutzer, Pseudo-completeness and the product of Baire

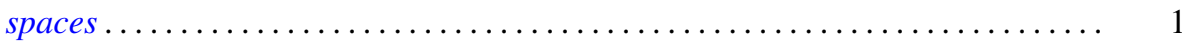

Gordon Owen Berg, Metric characterizations of Euclidean spaces ............ 11

Ajit Kaur Chilana, The space of bounded sequences with the mixed topology ..... . 29

Philip Throop Church and James Timourian, Differentiable open maps of

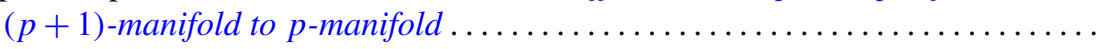

P. D. T. A. Elliott, On additive functions whose limiting distributions possess a finite

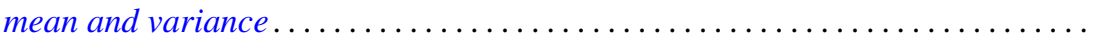

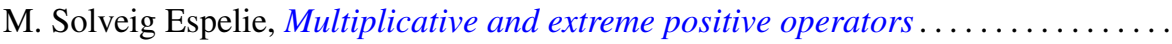

Jacques A. Ferland, Domains of negativity and application to generalized convexity

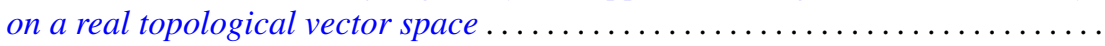

Michael Benton Freeman and Reese Harvey, A compact set that is locally holomorphically convex but not holomorphically convex ...............

Roe William Goodman, Positive-definite distributions and intertwining

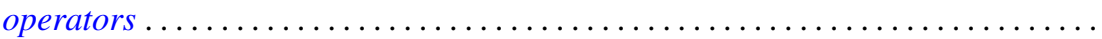

Elliot Charles Gootman, The type of some $C^{*}$ and $W^{*}$-algebras associated with

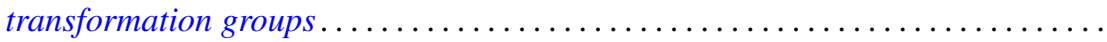

David Charles Haddad, Angular limits of locally finitely valent holomorphic

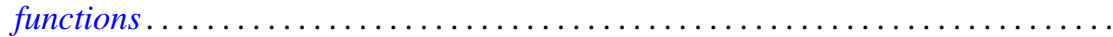

William Buhmann Johnson, On quasi-complements .

William M. Kantor, On 2-transitive collineation groups of finite projective spaces...

Joachim Lambek and Gerhard O. Michler, Completions and classical localizations of right Noetherian rings

Kenneth Lamar Lange, Borel sets of probability measures ......

David Lowell Lovelady, Product integrals for an ordinary differential equation in a Banach space

Jorge Martinez, A hom-functor for lattice-ordered groups .........

W. K. Mason, Weakly almost periodic homeomorphisms of the two sphere ....

Anthony G. Mucci, Limits for martingale-like sequences .......

Eugene Michael Norris, Relationally induced semigroups ...

Arthur E. Olson, A comparison of c-density and $k$-density ......

Donald Steven Passman, On the semisimplicity of group rings of linear groups.

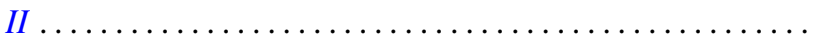

Charles Radin, Ergodicity in von Neumann algebras .

P. Rosenthal, On the singularities of the function generated by the Bergman operator of the second kind.

Arthur Argyle Sagle and J. R. Schumi, Multiplications on homogeneous spaces,

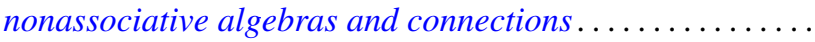

Leo Sario and Cecilia Wang, Existence of Dirichlet finite biharmonic functions on

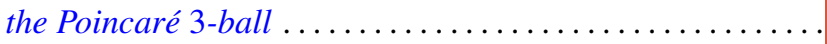

Ramachandran Subramanian, On a generalization of martingales due to Blake ..

Bui An Ton, On strongly nonlinear elliptic variational inequalities.

Seth Warner, A topological characterization of complete, discretely valued

fields. 